\title{
Observations of fish migration in a macrotidal mangrove channel in Northern Brazil using a 200-kHz split-beam sonar
}

\author{
Uwe Krumme *, Ulrich Saint-Paul \\ Zentrum für Marine Tropenökologie (ZMT), Fahrenheitstr. 6, 28359 Bremen, Germany
}

Accepted 11 April 2003

\begin{abstract}
A 200-kHz split-beam echosounder (BioSonics, DT6000) with a $6^{\circ}$ circular-beam transducer was applied in a mangrove channel in Northern Brazil to study the migratory patterns of intertidal fish. Acoustic sampling was conducted horizontally across the channel perpendicular to the tidal current during two lunar cycles in the dry season 2000 and the wet season 2001. The complex acoustic environment of the mangrove channel was characterized by small target sizes (juvenile fish), multiple targets (aggregated fish), high reverberation and background noise levels due to sediment loads, plankton and mangrove litter transport. Dry seasons provided less noisy acoustic conditions resulting in clearer echo data than wet seasons. Neap tide data were less complex than spring tide data. During a tidal cycle, low water provided the clearest acoustic conditions. Mangrove leaves generated fish-like echoes. Analysis of two dry season wax moon cycles revealed fish flux maxima at low water, flood start and high water in the daytime and the night cycle. Night fish fluxes were significantly higher than at daylight. Throughout the tidal cycles, $60 \%$ of the fish traveled with the tide and $40 \%$ against, suggesting active foraging against the tide to be a major component of fish movements. Resident mangrove fish entered the intertidal creeks at early flood tide, leaving at late ebb tide at fairly shallow-water depths. Estuarine fish required a minimum water depth (about $2 \mathrm{~m}$ ) for tidal migration. Since time delays during spring tides between immigration of resident and estuarine fish were reduced, foraging time and habitat accessibility would be enhanced and fish catches and fishes' feeding success would be greater.
\end{abstract}

(C) 2003 Éditions scientifiques et médicales Elsevier SAS and Ifremer/IRD/Inra/Cemagref. All rights reserved.

Keywords: Shallow-water echosounder; Mangrove; Fish migration; Tide; Tidal cycle

\section{Introduction}

Mangroves - the highly productive evergreen tidal forests - are considered important nursery areas for young fish throughout the tropical and subtropical coasts of the world (Bell et al., 1984; Robertson and Duke, 1987; Louis et al., 1995; Laroche et al., 1997; Barletta-Bergan et al., 2002). Interannual, seasonal, lunar and diel changes have been observed in mangrove ichtyofauna (Davis, 1988; Laegdsgaard and Johnson, 1995; Laroche et al., 1997; Barletta, 1999). These changes are caused by active movements of the fish in response to variations in food availability, presence of competitors, predation risk and environmental suitability (Gibson et al., 1998) on short-, medium- and long-term scales.

Since tidal-related short-time movements may play a large part in the everyday survival strategies of juvenile fish, com-

* Corresponding author.

E-mail address: uwe.krumme@zmt.uni-bremen.de (U. Krumme). prehensive information about such movements is essential for understanding the life of the young fish in their nursery habitats. Optimized small-scale movements within a nursery probably enhance growth, survival and thus recruitment success.

Although short-time changes in intertidal fish communities have been the focus of several studies (Davis, 1988; Laroche et al., 1997; Gibson et al., 1998; Krumme, own obs.), there is a considerable lack of detailed investigations on this particular time scale.

However, sampling in tidal habitats is often difficult to carry out (Horn et al., 1999). Generally, high tidal dynamics require high sample resolution and thus, sampling soon becomes labor-intensive. Additionally, strong tides and floating mangrove litter can considerably impede sampling with conventional fishing gear. Finally, low water clarity prevailing in many mangroves hampers visual observations of fish movements. 


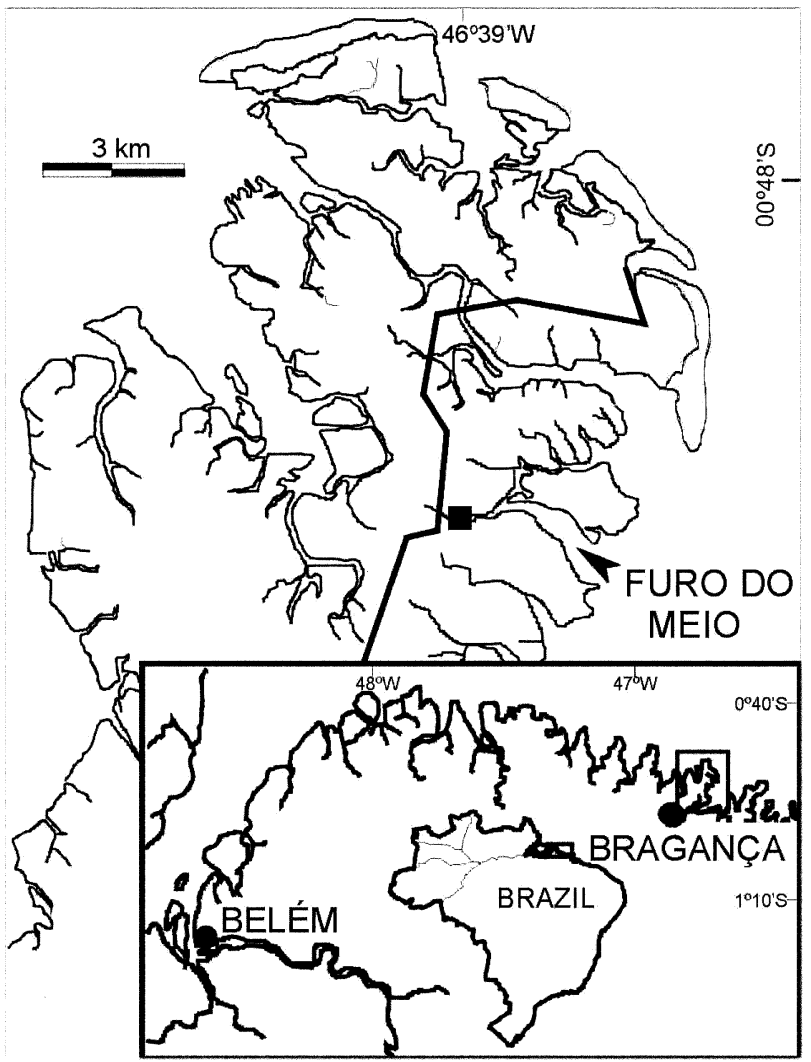

Fig. 1. Mangrove peninsula southeast of the Amazon estuary, $200 \mathrm{~km}$ east of Belém, North Brazil; location of the study site (Furo do Meio) in the center of the mangrove peninsula (black square) near the city of Bragança. Black line indicates road from Bragança to the beach.

Modern hydroacoustic equipment allows for nonintrusive, high-resolution sampling even in shallow-water environments. The tidally influenced fish behavior has been commonly observed in many estuaries and tidally influenced rivers (e.g. Levy and Cadenhead, 1995), albeit we found only one study which was conducted in a tropical mangrove environment (Guillard, 1998).

Within the scope of the MADAM project (Mangrove Dynamics and Management; Berger et al., 1999) we could apply a $200-\mathrm{kHz}$ split-beam sonar (BioSonics) in a macrotidal mangrove channel in Northern Brazil. Here, we present results about the tidal-related migratory dynamics of mangrove fish; critical phases for data acquisition in a mangrove environment are discussed.

\section{Materials and methods}

\subsection{Study area and site}

The study area, a $180 \mathrm{~km}^{2}$ peninsula located in the second largest mangrove area in the world (Spalding et al., 1997), is situated about $200 \mathrm{~km}$ east of Belém in the estuary of the Caeté river (Fig. 1) More than $4 / 5$ of the mangrove peninsula is covered by mangroves, predominantly Rhizophora mangle, Avicennia germinans on the more elevated sites, and rarely Laguncularia racemosa. A detailed description of the study area can be found in Krause et al. (2001).

The tidal regime is semidiurnal, ranging between 2.5 and $5 \mathrm{~m}$ at neap tides and spring tides, respectively. The region receives about $2500 \mathrm{~mm}$ of rainfall per year (INMET, 1992), mainly from January to June. Salinities (psu) can be below 5 in April and exceed 35 in November. Air and water temperatures are high year-round, ranging from 25 to $33{ }^{\circ} \mathrm{C}$ and $27-30{ }^{\circ} \mathrm{C}$, respectively. Water clarity is low $(5-30 \mathrm{~cm}$, max. $100 \mathrm{~cm}$ Secchi depth). Dittmar and Lara (2001a, b) provide further details about the dynamics of abiotic parameters.

The study site was located in the Furo do Meio, a large creek in the central part of the peninsula (Fig. 1) that has already been the sample site for several fisheries studies (Barletta, 1999; Barletta-Bergan, 1999; Krumme, own obs.; Leal-Flórez, pers. comm.; Brenner, pers. comm.). The Furo do Meio is a cul-de-sac channel with a length of about 4.5 $\mathrm{km}$. An extensive sand bank characterizes the lower reaches until $2.5 \mathrm{~km}$ upstream of the mouth. The upper reaches are composed entirely of mud providing an acoustically absorptive bottom boundary. Both the extreme upper and the entire lower reaches of the Furo do Meio are almost completely exposed to the air during low water (LW) (the deepest channel holds less than $5 \mathrm{~m}$ of water at LW). The sonar site was situated in the upper sector of the extensive subtidal section (1 km length) that extended to where the sand-dominated lower reaches started. Water depth at the sample site was $4 \mathrm{~m}$ at LW and could exceed $8 \mathrm{~m}$ at high water (HW). The channel width at the sonar site was $30 \mathrm{~m}$ at $\mathrm{LW}$ and about $50 \mathrm{~m}$ at $\mathrm{HW}$ (Fig. 2)

\subsection{Tidal-related acoustic sampling}

The 200-kHz split-beam sonar (Biosonics, DT6000) with a $6^{\circ}$ circular-beam transducer was employed horizontally across the channel perpendicular to the tidal flux Fig. 2 with acoustic ranges at neap tide between $14 \mathrm{~m}$ at LW and $23 \mathrm{~m}$ at HW. The transducer was fixed to an aluminum frame $(35 \mathrm{~cm}$ below the water surface), which was attached on two plastic floating bodies $(130 \times 25 \times 25 \mathrm{~cm}$ each). The horizontal position of the floating device was adapted to the changing water levels using four different positions (P1: HW, P2 and P3: intermediate, P4: LW). At each position, the four corners of the floating device were moored on four wooden sticks that determined the position. Thus, the transducer could float within each position while the transducer's orientation remained steady (no pitch and roll).

\subsection{Data acquisition}

Acoustic data were collected during two successive lunar cycles: a dry season from September to November 2000, and a wet season from March to May 2001. For each lunar phase, data were continuously acquired for $50 \mathrm{~h}$, thus covering four consecutive tidal cycles. The transmission rate of the sound pulses was four pings per second. A narrow pulse-width of $0.2 \mathrm{~ms}$ was chosen to maximize the range-resolution of 


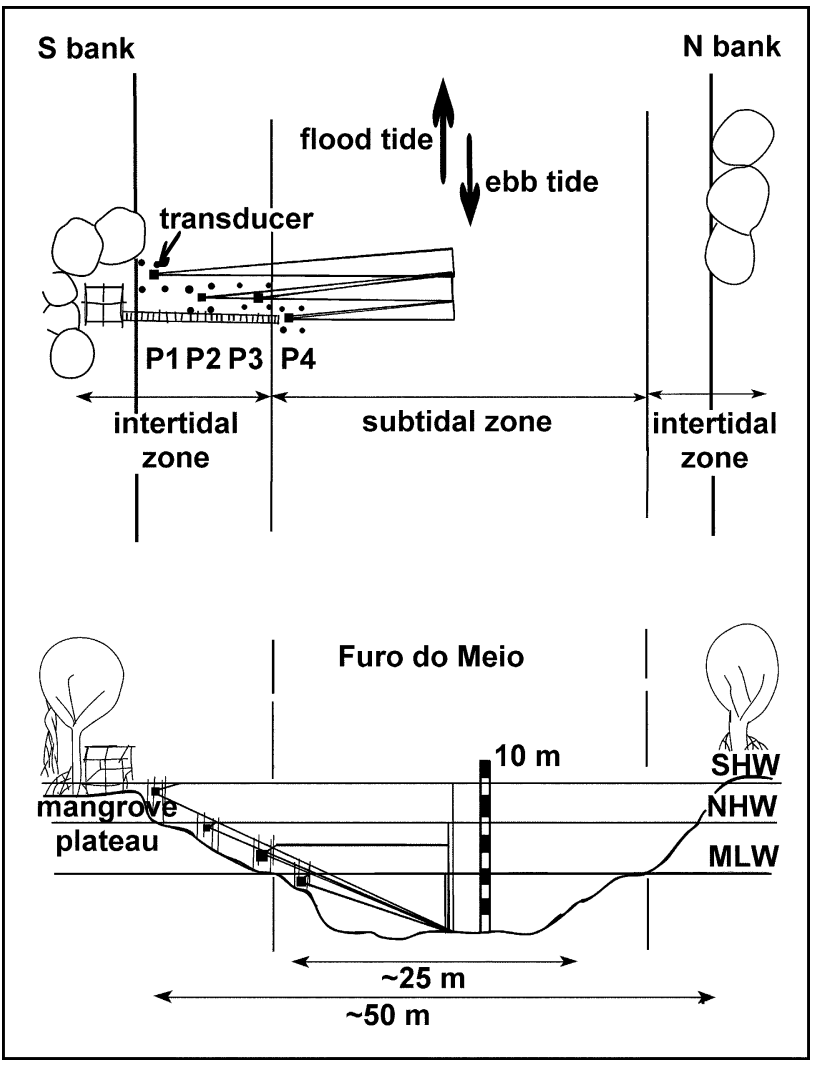

Fig. 2. Tidal-related acoustic sampling in the Furo do Meio. Aerial (above) and cross-sectional view (below) of sonar site. Insonified portions of the channel at different tidal stages (schematic drawing). P1: transducer high water position, $\mathrm{P} 2$ and $\mathrm{P} 3$ : intermediate positions, $\mathrm{P} 4$ : LW position. SHW = spring tide high water; NHW = neap tide high water; MLW = mean low water.

individual fish and to minimize reverberation levels. Low ambient noise (beyond $-80 \mathrm{~dB}$ ) allowed for a threshold of $-70 \mathrm{~dB}$. The acquisition software (Visacq 4.0.2, BioSonics) was run $5 \mathrm{~min}$ on and $5 \mathrm{~min}$ off continuously throughout $50 \mathrm{~h}$.

Abiotic cycles were measured constantly during each sonar sampling (water level, salinity, Secchi depth, water temperature, wind). We inferred current velocities from a relationship established between current velocity $\left(\mathrm{m} \mathrm{s}^{-1}\right)$ and water level change (height change $\mathrm{min}^{-1}$ ) during 16 neap tide tidal cycles in the Furo do Meio in October and November 2002. The neap tide tidal curve was subdivided into five different parts and five linear or polynomial regressions were calculated fitting best the relationship between water level change and current velocity: (1) LW until about $1.1 \mathrm{~m}$ after start of flood tide, (2) >1.1 m until HW, (3) HW until maximum ebb tide, (4) maximum ebb until about $1.1 \mathrm{~m}$, (5) $<1.1 \mathrm{~m}$ until LW. Approximately $1.1 \mathrm{~m}$ above LW corresponds to the topographical height where the lateral mangrove creeks enter the main channel.

\subsection{Calibration}

The DT6000 was professionally calibrated by BioSonics (Seattle, USA). Since in situ calibration was uncorroborated by the tidal current and in the occasionally strong wind, calibration (tungsten carbide sphere) was performed in a black water pool (0 psu, $\left.28{ }^{\circ} \mathrm{C}\right)$ in Bragança (Pará, Brazil) and in a brackish water mangrove lagoon $\left(10 \mathrm{psu}, 29^{\circ} \mathrm{C}\right)$ near the sample site. The mean target strength (TS) value for the sphere of $-39.8 \mathrm{~dB}( \pm 2.59$ S.E., $n=229$ echoes; pool) and $-40.5 \mathrm{~dB}( \pm 1.00$ S.E., $n=1727$ echoes, lagoon) corresponded closely with the theoretical value of $-40.0 \mathrm{~dB}$ (both calibration files analyzed with VisAnal4.0.2).

\subsection{Data processing}

Two dry season wax moon tidal cycles (October 6-7 and November 5-6) were analyzed for fish tracks using Vtrack1.0.1 (BioSonics software). Since different acoustic conditions occurred at different tidal stages, we adopted an analysis strategy in which each 5-min-file was run several times with varying parameter sets. Thus, we tried to minimize the noise and maximize fish echo recognition performance. The Vtrack software showed the track formation results visually, and track formation parameters were selected to optimize the formation of fish tracks. Thus, different minimum TS limits were used for different files acquired during a tidal cycle. One single TS limit would have provided a better interfile-comparability in terms of target size. The median Vtrack TS limits applied during tracking analysis for the neap tide cycles in October and November were $-52 \mathrm{~dB}$ (S.D. $=4$, S.E. $=0.3, \min -60 \mathrm{~dB}, \max -43 \mathrm{~dB}$ ) and $-55 \mathrm{~dB}$ (S.D. $=4$, S.E. $=0.3, \min -63 \mathrm{~dB}, \max -43 \mathrm{~dB}$ ), respectively. We found a range-dependent bias in the TS measurements between Vtrack and VisAnal (both programs BioSonics) that followed a power function $\left(y=7.8906 \times x^{-0.7481}\right)$ with highest bias in less than $5 \mathrm{~m}$ range (e.g. Vtrack TS was $6 \mathrm{~dB}$ higher at $3.5 \mathrm{~m}$ range) and decreasing bias with increasing range ( $>1 \mathrm{~dB}$ beyond $15 \mathrm{~m}$; J. Dawson, pers. comm.). All other parameters like range, angles or beam pattern correction values were calculated the same by the two programs (J. Dawson, pers. comm.). Given the TS difference, we decided to leave out a detailed analysis of the TS values.

To determine the fish flux in front of the transducer, we calculated the cross-section intercepting the movements of the fish; dividing the number of up- and downstream fish tracks by the cross-section area per unit time provided a straightforward algorithm in the form number of fish $\mathrm{m}^{-2}$ $\min ^{-1}$.

\section{Results}

\subsection{Acoustic characterization}

\subsubsection{Season}

The dry season provided better acoustic conditions than the wet season, when terrestrial run-off in the catchment area increased sediment loads in the entire Caeté estuary and in the mangrove channels. In the mangrove proper, rains eroded fine sediments from the forest floor into the channels, with poorest acoustic conditions in the channels' upper reaches 
(increased background reverberation, decreased signal-tonoise ratio). During wet season neap tide-LW, when the tide was almost stagnant, the water had quasi-viscose properties due to the high concentrations of fine sediment particles. Sound was completely absorbed for hours (white sonar files) until the next flood tide. This phenomenon disappeared when the rains retreated. During rain showers, ambient noise levels in the water increased and occasionally completely concealed targets, thus generating phases of the missing data.

\subsubsection{Tide}

Acoustic conditions at spring tide were by far more complex and hence poorer than at neap tide. At spring flood tides, the water level rose more than $2 \mathrm{~m}$ in less than $1 \mathrm{~h}$ Fig. 6 . Extreme tidal rise or fall at spring tide always correlated with minimum Secchi readings and maximum seston transport, thus deteriorating acoustic conditions (see above). At spring tide HW, the mangrove floor was usually inundated. About $3 / 4$ $\mathrm{h}$ after HW, the export of huge amounts of mangrove litter (particularly buoyant leaves) started and lasted for about 11/2 h. During each spring ebb tide, this phenomenon was observed on the channel surface as concrete convergence-like surface bands at the zone where the ebb current was supposed to be strongest, and on the echogram as undulating bands with high TS values. Common software cannot analyze the increased structural complexity in the channel.

\subsubsection{Tidal phase}

The tide was asymmetric, flood and ebb tide lasting between 4 and $8 \mathrm{~h}$, respectively. In the last $4 \mathrm{~h}$, ebb tide was extremely weak with an almost negligible fall in the water level. Consequently, different acoustic conditions occurred at different tidal stages. The best acoustic conditions prevailed during weak ebb tide when the tidal impact was insignificant (signal-to-noise ratio (SNR) at LW: ca. $15 \mathrm{~dB}$ ).

Acoustic conditions at strong flood tide and strong ebb tide were poorest due to increased background reverberation. Weak flood tide, HW and weak ebb tide provided intermediate acoustic conditions (SNR at HW: ca. $7 \mathrm{~dB}$ ).

\subsection{Abiotic parameters}

Secchi disc readings at dry season-neap tide were positively correlated with water level (LW 20-30 cm; HW 70-90 $\mathrm{cm})$. Extreme tidal rise or fall coincided with minimum Secchi readings, maximum seston transport and current velocity maxima. Neap tide current velocitieswere asymmetric. Flood and ebb tide speeds reached maxima of almost 25 and $15 \mathrm{~cm} \mathrm{~s}^{-1}$, respectively (Fig. 3 upper figures). Current velocities were highly dynamic, with irregular and strong changes in speed within a few minutes. During weak flood tide intervals, even complete changes to ebb direction occurred. Salinity (psu) increased from 29 in October to 33 in November. Salinity was negatively correlated with water level (cycle maxima at LW, minima at HW). Oxygen and water temperature followed a $24 \mathrm{~h}$ cycle, reaching highest values in the late afternoon at ebb tide $\left(9.5 \mathrm{mg} \mathrm{l}^{-1}\right.$ and $30{ }^{\circ} \mathrm{C}$,
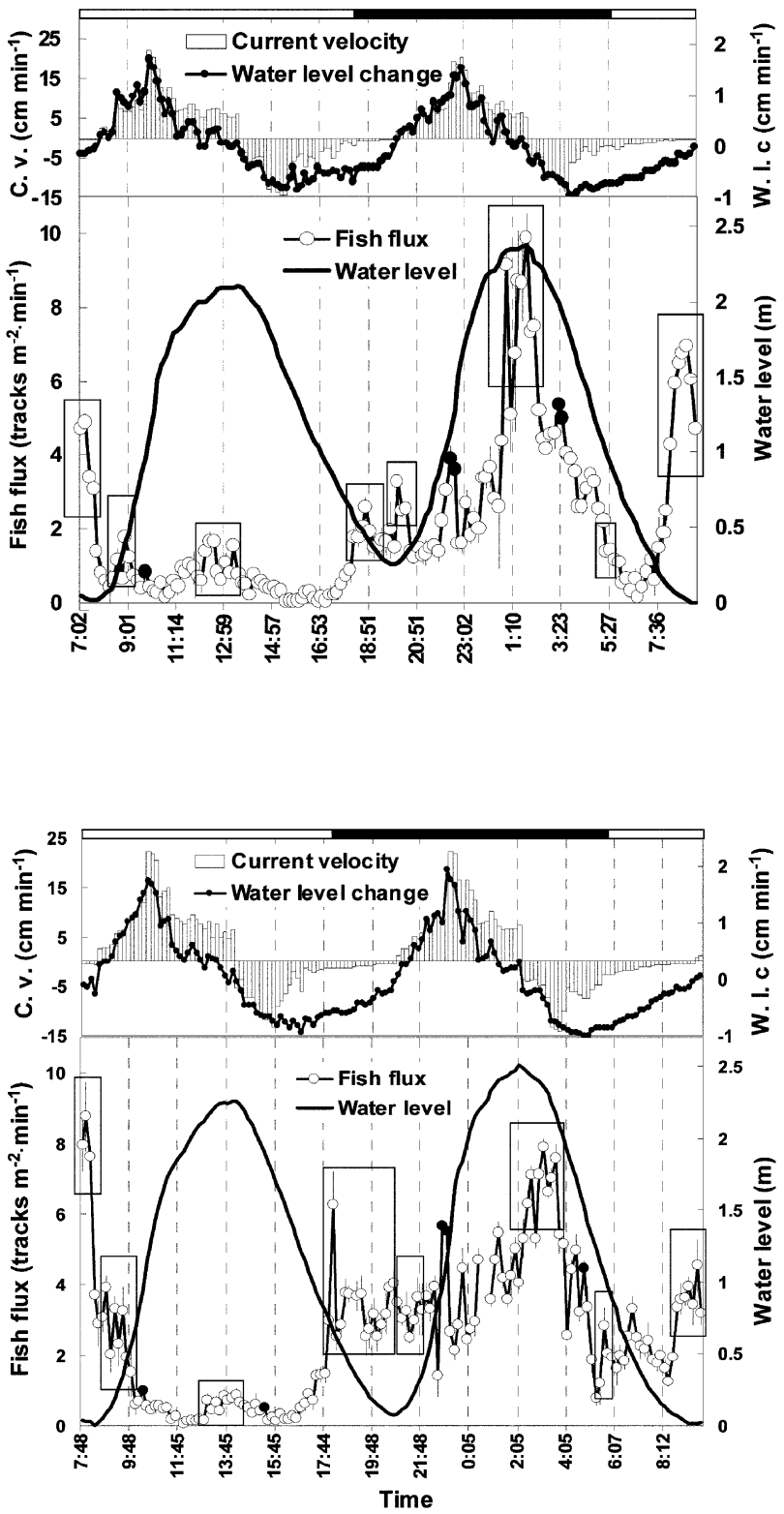

Fig. 3. Mean fish flux (fish $\left.\mathrm{m}^{-2} \mathrm{~min}^{-1}\right) \pm 1$ S.E. and tidal curve (lower figure) and current velocities (bars) derived from the water level change (upper figure) at two wax moon cycles (neap tide), October 6-7 (above) and November 5-6 (below), during dry season 2000, in the Furo do Meio. Horizontal bars on top indicate night ( 18 h $00-5$ h 45$)$. Lower figure: rectangles indicate fish flux peaks at daytime-LW, daytime-flood start, daytime-HW, night-LW, night-flood start, night-HW, dawn and again daytime-LW (from left to right). Closed circles indicate distinct fish flux peaks at increased current velocities.

respectively). Lowest water temperatures were recorded during the night-HW $\left(28{ }^{\circ} \mathrm{C}\right)$. Lowest oxygen values were recorded at 7:30 $\left(6 \mathrm{mg}^{-1}\right)$. Wind consistently blew in from the northeast with stronger periods both in the afternoon and in the night.

\subsection{Fish tracking}

About 30000 fishes were detected during each neap tide cycle. Assuming that half of the channel cross-section was 

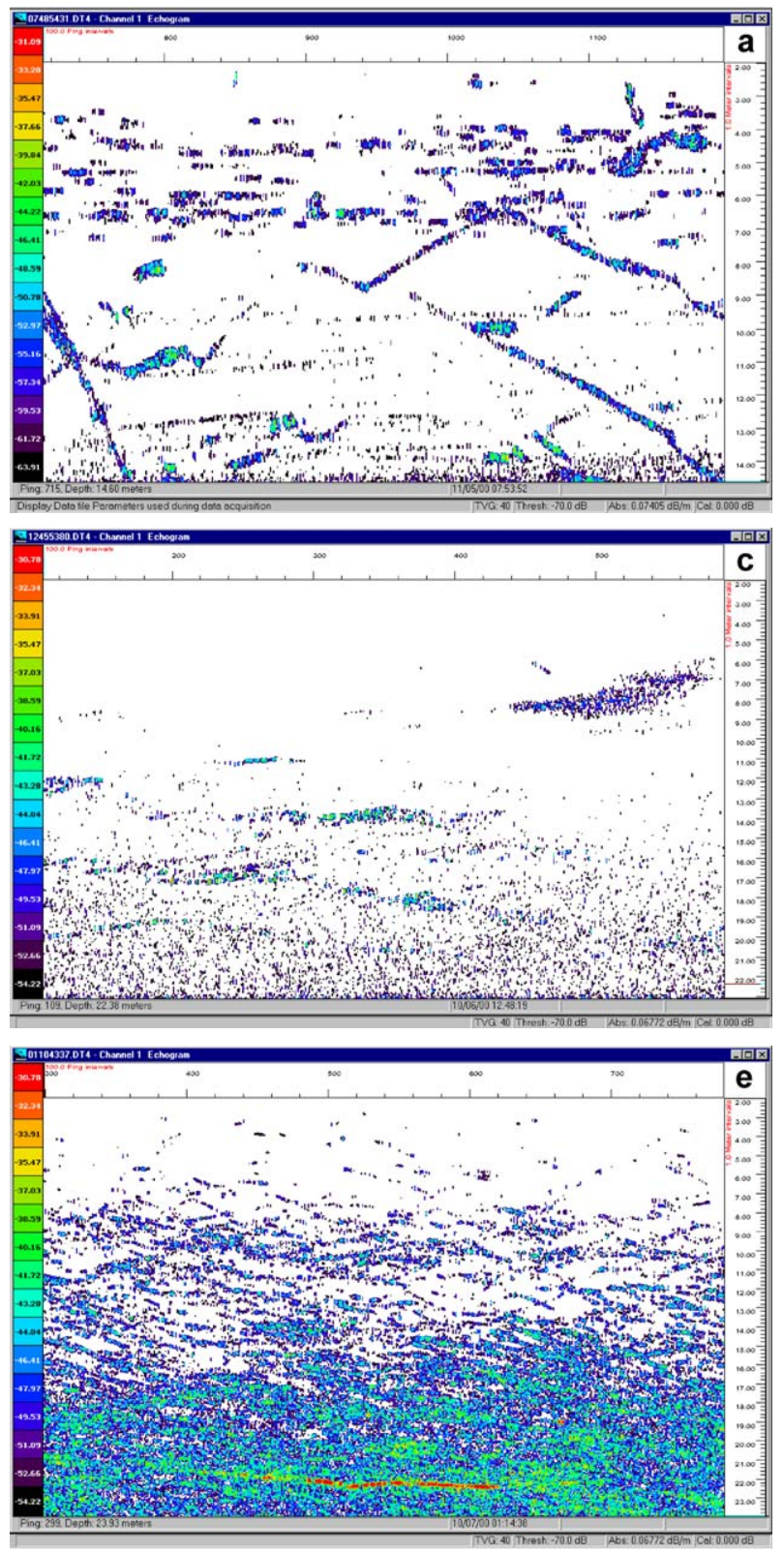
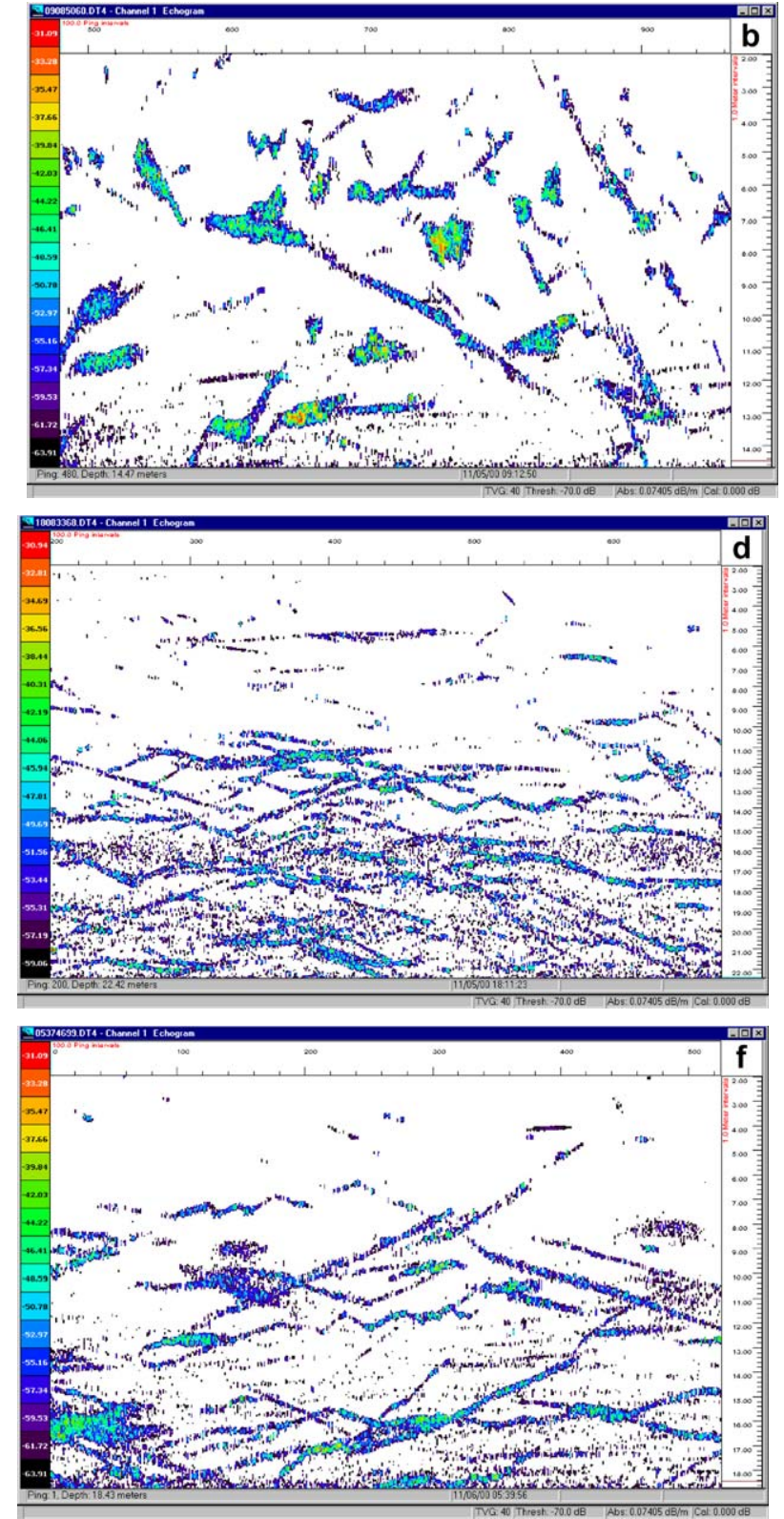

Fig. 4. Examples of echograms from fish flux peaks in the mangrove channel Furo do Meio near Bragança, PA, North Brazil, neap tides, during dry season 2000, at (a) daytime-LW, 7 h 54, November 5, 2000; (b) flood tide start at daytime, 9 h 13, November 5, 2000; (c) daytime-high water, 12 h 48, October 6, 2000; (d) night-LW at sunset, $18 \mathrm{~h} \mathrm{11,} \mathrm{November} \mathrm{5,} \mathrm{2000;} \mathrm{(e)} \mathrm{night-high} \mathrm{water,} 1$ h 14, October 7, 2000 and (f) sunrise, 5 h 40, November 6, 2000. Echogram axis, left: echo intensity (dB; red strongest); right: range in front of transducer $(\mathrm{m})$; top: time ( 2 min period or about 480 pings at a ping rate of 4 pings $\mathrm{s}^{-1}$ ); bottom: first bottom echo. Note different scales for range and echo intensity between echograms.

insonified and considering only fish moving upstream, we calculated a mean of 6000 and 28000 fish immigrating into the mangrove during the daytime and the night flood tide, respectively.

The fish flux curves of both dry season neap tide cycles had seven peaks: at daytime-LW, the start of daytime flood, daytime-HW, night-LW (starting at dusk), the start of night flood, night-HW and at dawn Fig. 3. The daytime-LW peak occurred in the morning (5-9 fish $\mathrm{m}^{-2} \mathrm{~min}^{-1}$ ) with highest values at slack low tide just before the water level started to rise again. A unique migratory pattern was observed during the daytime-LW peak when many targets occurred in a near- range corridor along the southern side of the channel and several tracks were visible in the far range (Fig. 4a) At the start of the daytime flood tide when current velocity increased sharply, fish fluxes peaked to about 2 fish $\mathrm{m}^{-2} \mathrm{~min}^{-1}$ showing an upsurge in activity with many multiple targets occurring and crisscrossing throughout the range Figs. 3 and $4 \mathrm{~b}$. At the end of the daytime flood tide, fish flux increased slightly to form the daytime-HW peak, albeit reaching only about 1 fish $\mathrm{m}^{-2} \mathrm{~min}^{-1}$ Figs. 3 and $4 \mathrm{c}$. The night-LW peak started at dusk. The fish flux remained high throughout the night LW phase and ended when the night-flood tide started (about 2-3 fish $\mathrm{m}^{-2} \mathrm{~min}^{-1}$; Figs. 3 and 4 d. The night flood 


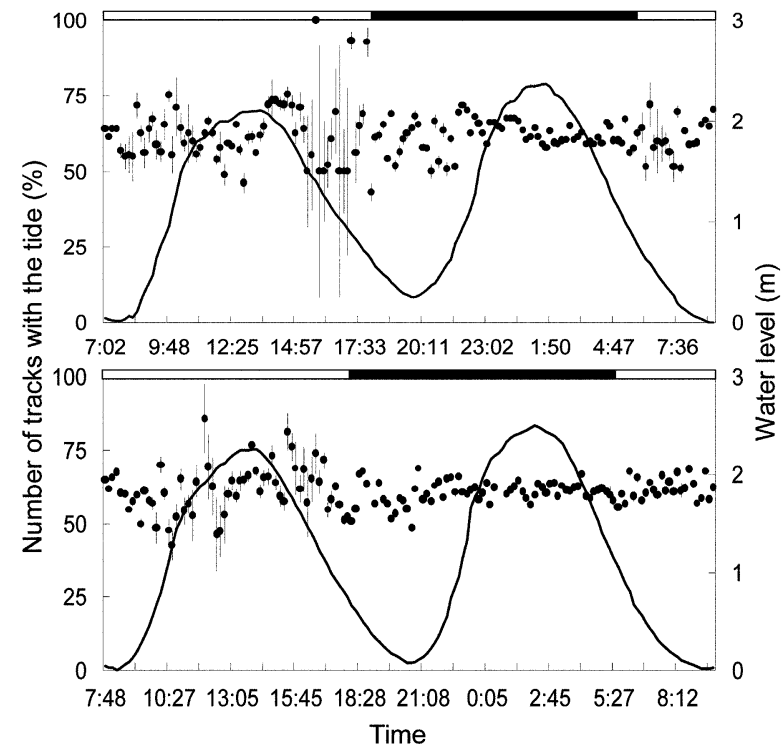

Fig. 5. Proportion of fish tracks going with the tide (solid circle \pm 15 S.E.) and tidal cycle (solid line) for two neap tide cycles, October 6-7 (above) and November 5-6 (below). Black bars on top indicate night (18 h 00 until $5 \mathrm{~h}$ 45). High S.E. is related to low sample size (number of fish tracks) since variance was $p \times\left[(1-p) \times n^{-1}\right]$ with $p=$ proportion of fish tracks going with the tide.

start peak occurred at a fish flux level similar to the previous night-LW peak (about 2-3 fish $\mathrm{m}^{-2} \mathrm{~min}^{-1}$ ). The distribution pattern of target tracks resembled the night-LW situation; unlike the start of daytime flood tide, night flood start lacked multiple targets. The night-HW peak also started at the end of flood tide (5-10 fish $\mathrm{m}^{-2} \mathrm{~min}^{-1}$ ); many target tracks occurred throughout the range Figs. 3 and 4e . At dawn, fish fluxes increased briefly (Fig. 4f). After sunrise, fish flux was low until the daytime-LW was formed again towards the end of weak ebb tide. In contrast to the clear fish flux increase at dusk, fish flux increase at dawn was weak [Figs. 3 and 4d,f]. Individual fish flux maxima coincided with strong flood and ebb tide intervals Fig. 3. Mean fish flux was 2.4 fish m ${ }^{-2}$ $\min ^{-1} \pm 2.1$ S.D. The night fish fluxes, especially at HW were several times higher than those at daytime. Due to the particular flux patterns at daytime-LW, however, the LW fish flux peak was usually higher at daytime than at night.

Target sizes were generally small $(-43 \pm 4 \mathrm{~dB}, n=55727$; results from Vtrack), indicating the presence of mainly juvenile or small-sized fish. Larger echoes $(>-30 \mathrm{~dB})$ were usually only caused by multiple targets.

Throughout the tidal cycles, about $60 \%$ of the fish tracks were directed with and about $40 \%$ against the tide Fig. 5 , with higher variability in the proportions occurring during the daytime cycle. A tidal periodicity was not apparent.

\section{Discussion}

\subsection{Acoustic characterization}

It was a clear advantage that the sampling period started in the dry season. Thus, we became acquainted with the yet

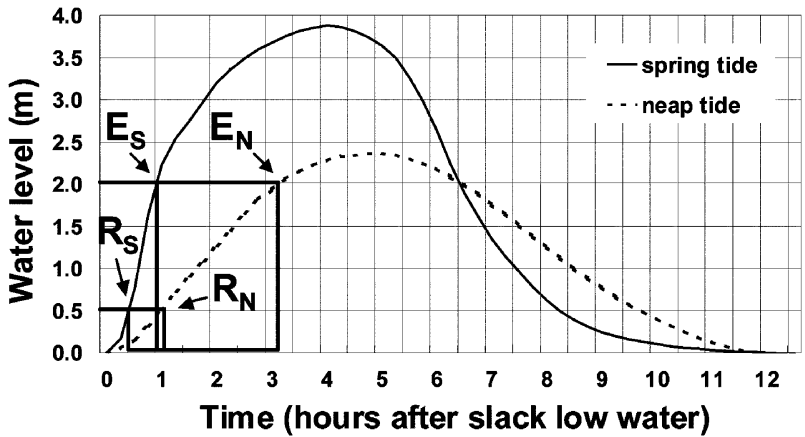

Fig. 6. Time delay threshold between spring tide and neap tide in mangrove accessibility at two water levels; $\mathrm{E}_{\mathrm{S}}$ : Estuarine fish at spring tide, $\mathrm{E}_{\mathrm{N}}$ : Estuarine fish at neap tide, $\mathrm{R}_{\mathrm{S}}$ : Resident fish at spring tide, $\mathrm{R}_{\mathrm{N}}$ : Resident fish at neap tide.

unknown acoustic conditions in the mangrove environment under a minimum of external influences. The poor acoustic conditions encountered in the wet season might hold true for turbid shallow-water environments on tropical coasts in general. Experiments using vertical transducer orientation or the use of a lower frequency echosounder $(120 \mathrm{kHz}$ instead of $200 \mathrm{kHz}$ ) could be worthwhile alternatives.

When studying intertidal migration patterns of fish acoustically, it is very problematic when the clearest conditions for sonar application occur at weak ebb tide when tidal impact is negligible. Fortunately, weak neap tide currents allowed for sonar file analysis throughout the tidal cycles.

\subsection{Fish tracking}

Considerable numbers of fish entered the upper reaches of the mangrove during flood tides. The high numbers can be attributed to the high abundances of juvenile fish commonly found in mangroves (Sasekumar et al., 1992; Laedgsgaards and Johnson, 1995; Barletta, 1999).

The high number of target tracks, their relatively low TS values and a mean fish size of $14 \mathrm{~cm}$ in the mangrove channels (Krumme, own obs.) clearly emphasized the importance of this habitat as a fish nursery.

The hypothesis that intertidal fish behave like passive particles can be readily rejected since a considerable proportion of the tracks (about 40\%) was directed against the tidal current irrespective of flood or ebb tide. However, the high background noise levels observed in the channel may have added higher variability to the positional data of the splitbeam system (Kieser et al., 2000; Fleischman and Burwen, 2000) and could have led to incorrect results when assigning the track directions. It is nevertheless clear that the fish are not passively transported by the tides but may in fact actively move to, and concentrate in resource-rich intertidal habitats when accessible. Obviously, swimming against the direction of the tide was a major component of fish movements in the mangrove channel at neap tide. Thus, surface and midwater fish may take advantage of the fact that food is passively transported towards their mouth. Colomesus psittacus (Tetraodontidae) was observed maintaining its relative position 
in the channel while actively swimming against the current near the water surface. Thus, they patrolled a certain corridor for several minutes searching for prey. This particular swimming behavior of $C$. psittacus was reflected on the echogram as extraordinarily long tracks. Position shifts to the left or to the right may have caused the zick-zack tracks visible on the echograms Figs. 4a,f.

We assume that the fish swam and crisscrossed in the flooding and ebbing water body to inter- and intraspecifically increase their particular foraging areas while taking advantage of the tidal transport into and out of the intertidal area. Weak neap tide current speeds did not constrain fish to show strong directional movements. Nevertheless did fish fluxes noticeably increase during short intervals of increased current speed suggesting a positive response of the fish to increased tidal current speeds Fig. 3.

\subsection{Tidal stage}

LW and HW phases represented stable stages with established fish assemblages at increased fish fluxes; unlike flood and ebb tides that can be considered as transitional stages during the tidal migration of fishes. Detailed stomach analysis of the catfish Cathorops sp., predominant in the upper reaches of the channels (Barletta, 1999), revealed that flood tide stomachs were generally empty, whereas ebb tide stomachs were already well filled briefly after HW (Leal-Flórez, pers. comm.). Apparently, the tidal stages before and around HW were the principal phases for catfish feeding. This pattern corresponded well with the fish flux peaks around HW in the channel. Although benthic catfish may not have been well represented by horizontal beaming, their foraging pattern can serve as a general rule for more pelagic fish species as well since the water level likewise determines the degree of habitat accessibility for other intertidal fish.

It seems contradictory that fish fluxes increased at HW when the water volume was greatest. However, we assume that the immigration and import of organisms from downstream was maximum at HW. Both nekton abundance and species richness were significantly greater at slack high tide than either flood or ebb tide on a temperate marsh surface (Kneib and Wagner, 1994). HW is the short period where insignificant current speed and maximum intertidal accessibility coincide. Water transparency was highest at and after HW. Fish that actively immigrated into the mangrove during flood tide probably milled around at HW in the main channel, especially during the night-HW Fig. 4e. The increased fish flux at HW clearly indicates that active movements in the water column increased. We assume that negligible current speed and high water transparency around HW favored visual focusing of pelagic prey by the fish in the mangrove water, both at day and at night. Insignificant current speeds at slack HW probably favored localization and oral fixing of benthic prey in the mud.

The high fish fluxes at LW resulted from the resident fishes' active swimming in the subtidal parts of the channel. The population of resident mangrove fish probably achieved successful maintenance in the channels' upper reaches by late emigration out of the intertidal mangrove creeks. Thus, they would both achieve avoidance of undesirable downstream transport and optimize the time for feeding in the intertidal creeks. Staying horizontally in distance to the main channel is probably linked to rather bottom-oriented movements at ebb tide. Interconnected to the fish community, similar temporal patterns with stable assemblage structures during HW and LW can be proposed for other tidally influenced nekton communities, e.g. zooplankton (Krumme and Tsui-Hua, submitted) and phytoplankton organisms (Schories et al., unpubl.).

\subsection{Migratory cycle}

The course of the flux curve and the series of sonar files suggest a schematic migratory cycle for intertidal mangrove fish. The migratory pattern found for the two wax moon cycles to all appearances also applies to wane moon cycles, thus reflecting a typical dry season neap tide pattern in 2000 .

1. Resident mangrove fish were clearly concentrated in the subtidal parts of the channel forming both the LW peak at daytime and at night Fig. 3.

2. As soon as the water level started to rise at the start of flood tide, fish flux first peaked and then decreased. Resident fish either left the channel horizontally entering the shallow (less than $50 \mathrm{~cm}$ ) intertidal creeks, or went down towards the channel bottom. We assume early horizontal immigration into the mangrove creeks since a clear upsurge in fish activity during the first 30 min after slack low tide was observed on the echograms Fig. 4b. Cattrijsse et al. (1994), using a fyke net in a Dutch marsh, found that most species migrate during the first and the last hours of the tidal cycle when the current velocities were low; gill net catches of summer flounder in New Jersey were greatest in early flood tides and in mid and late ebb (Rountree and Able, 1992).

3. During flood tide, distinct fish flux maxima coincided with current speed maxima. The mangrove fish community apparently directly responded to the tidal current regime on a very short time scale.

4. During flood tide, the fish fluxes increased towards HW. Many resident mangrove fish were probably foraging in the intertidal mangrove creeks at this time and hence absent from the main channel. Fish fluxes in the mangrove channel did not increase until the flood tide water level had risen about $2 \mathrm{~m}$ above the previous LW level and flood current speeds had fallen below $10 \mathrm{~cm} \mathrm{~s}^{-1}$ (upper figures in Fig. 3. Estuarine fish that immigrated with the flood tide from the Caeté estuary to the upper reaches (a distance of at least $4 \mathrm{~km}$ ) probably contributed to the HW fish flux peak. Several other authors have assumed that some estuarine fish require a minimum water level to enter an intertidal area (Davis, 1988; Blaber et al., 1994). Interestingly, Gibson (1973) counted most fish in an intertidal Scottish sandy beach when the water was 1-2 m deep. Prey search of pelagic 
Table 1

Lift net catches in main channel of the mangrove creek Furo do Meio, dry season 2000; sunrise was at 5 h 45 , sunset at 18 h 00 ; data from Leal-Flórez (pers. comm.)

\begin{tabular}{lllll}
\hline Species & Total & $\%$ & Day & Night \\
\hline Cathorops sp. & 735 & 39 & 316 & 158 \\
Sciaenidae & 468 & 25 & 192 & 310 \\
C.psittacus & 229 & 12 & 81 & 37 \\
Engraulidae & 137 & 7 & 169 & 143 \\
Others & 312 & 100 & 916 \\
Sum & 1881 & & 965 \\
\hline
\end{tabular}

and benthic fish in the channel was probably facilitated (see above) and hence resulted in increased milling in front of the transducer around HW.

5. When the water levels in the mangrove channel started to fall with the receding tide, fish flux decreased again. The decrease in fish flux during ebb tide occurred at water depths apparently symmetrical to those at flood tide Fig. 3. When we assume that estuarine fish returned to the start points of their tidal migration, they covered distances of at least $8 \mathrm{~km}$ for each tidal cycle between the estuary and the upper mangrove reaches. The emigration of estuarine fish out of the mangrove channels during ebb tide is exploited by local fishermen with large fish traps (corrals) on the sand banks of the lower reaches of the channels and in the estuary (Barletta et al., 1998; Schaub, pers. comm.). Resident mangrove fish may have returned from the intertidal creeks to the channel at mid or late ebb tide as observed by Rountree and Able (1992) for summer flounder where they stay until the next flood tide enters again. A signal from this emigration was not apparent in the sonar files, possibly due to more bottom-oriented movements. The fish flux rather showed a continuous decrease. However, like at flood tide did distinct ebb fish flux maxima coincide with ebb current speed maxima.

6. At neap tides, twilight coincided with the semistagnant LW phase. Especially at dusk fish flux increased significantly whereas sunrise only produced a weak signal in the fish flux curves. Most mangrove fish are rather nocturnal or show at least negative phototaxis (own obs.); only $C$. psittacus is a clear diurnal species (Table 1).

\subsection{Delay in accessibility}

The accessibility of the intertidal area is determined by the water level, i.e. the height of the tide. Since resident and estuarine fish apparently accessed the intertidal mangrove area at different water levels, the time delay between the two access levels determines the time available for mangrove foraging. Fig. 6 shows the extremely short-time delay between habitat accessibility for resident and estuarine fish at spring tide and the rather marked time delay for neap tides. Resident mangrove fish may spend more time feeding in the mangrove than estuarine fish whose foraging activity is more restricted in time, especially at neap tide (Fig. 6). The high standing stocks of resident Cathorops sp. and Anableps anableps (Barletta, 1999; Krumme, own obs.) compared to other fish species captured in the upper reaches of the mangrove channel at HW support this argument. For estuarine fish, the time delay between the start of flood tide until a minimum water depth provides access to the intertidal area, may be a crucial parameter for intertidal migration of estuarine fish. Hence, the hydrodynamics at spring tide provide excellent conditions for immigration of estuarine fish since the mangrove becomes accessible in less than an hour after slack LW, unlike more than $3 \mathrm{~h}$ during neap tides Fig. 6. The numbers of 11 fish species were greater at spring tides (Krumme, own obs.) when both the periods available for foraging and the habitat accessibility in the mangrove are increased Fig. 6. Foraging success of A. anableps, Arius herzbergii and Anchovia clupeoides was clearly greater at spring than at neap tide (Brenner, pers. comm.).

\subsection{Four assemblages}

We assume that different fish assemblages caused each of the fish flux peaks at LW and HW during a neap tide cycle. Krumme (own obs.) already found that HW assemblages of mangrove fish at neap tide differ significantly between day and night with the neap tide-daytime assemblage being poorest in both biomass and diversity. This might explain the marked increase of fish tracks throughout the night cycle compared to the desolated track situation during the daytime cycle. Morrison et al. (2002) found clear differences in the fish fauna composition between both low and high tides and day and night samples in a temperate New Zealand tidal mudflat. Simultaneously to the sonar application during the dry season 2000, Leal-Flórez (pers. comm.) caught migrating fish $500 \mathrm{~m}$ upstream of the sonar site in the open channel from a bridge using lift nets. Day and night catches were similar in terms of abundance but differed clearly in their species composition Table 1. Cathorops sp. was constantly present in the catches. Sciaenidae, a mainly nocturnal family (Helfman, 1993) was more abundant at night and may have caused the high numbers of targets at night-HW. The diurnal pufferfish $C$. psittacus was mainly caught during daylight. Engraulidae tended to be more abundant at daytime as well. These species may have contributed to the daytime-HW fish flux peak. Unfortunately, there was no relationship between the number of fish caught (lift nets) and the number of fish 
tracked (counting of acoustic traces). The lift net did not produce representative catches. It suffered from several shortcomings: during strong spring flood and ebb tide the lift nets flouted. They became frequently entangled in the channel bottom near the bridge, and clearing of the net might have expelled fish from the area. LW depth at the Furo do Meio bridge was less than $1 \mathrm{~m}$, hence complicating lift net use.

Our findings suggest that different assemblages also existed for LW day and LW night during neap tide. Increasing fish fluxes at the night-LW coincided with sunset and remained high throughout the LW phase Figs. 3 and 4d). During the daytime LW phase, fish fluxes peaked weakly at sunrise. This was probably caused by an activity upsurge of C. psittacus. At dawn, lift nets again caught C. psittacus (Leal-Flórez, pers. comm.). Fish fluxes then only increased after 7:00, peaking towards 9:00 at slack low tide. Maybe the formation of the near-range corridor at LW, i.e. increasing fish fluxes, was related to the increased oxygen concentrations after the oxygen minimum at around 7:00 (start of phytoplankton activity during the stable weak ebb tide). Barletta-Bergan (1999) found at neap tide in the same mangrove area, high densities of five fish species: early larval stages of $<10 \mathrm{~mm}$ of $A$. clupeoides (Engraulidae), Stellifer sp. (Sciaenidae), Rhinosardinia amazonica (Clupeidae), Archirus sp. and Guavina guavina (Eleotridae) in the morning (9:00), predominantly occurring at the surface, probably feeding on plankton. Densities of larval and juvenile fish were significantly lower during the night-LW (21:00) for most taxa except for Stellifer rastrifer, which showed significantly higher values at night (Barletta-Bergan, 1999). Furthermore, Fig. 4d shows clearly that the horizontal distribution and movement pattern of targets was different between the daytime and the night LW situation. During the night-LW, multiple targets did not occur and the near-range corridor was absent, suggesting different assemblages to be active at these periods. However, it remains unclear whether the nearrange band of targets at daytime-LW represented a typical feature of the system or whether it was merely caused by an extraordinary abundant cohort in its nursery ground. Spring tide LW lacked any similar horizontal pattern in the target distribution.

\section{Conclusions}

The observation of fish movements using shallow-water acoustics was feasible in a mangrove environment. Shallowwater acoustics provided a reasonable approach to obtain high-resolution samples in a dynamic environment where conventional fishing methods have become limited. For acoustic studies in tropical estuarine environments, we recommend sampling during the dry season and at weaker tides, that is, at neap tide and/or during LW.

Fisheries studies conducted under meso- or macrotidal regimes should consider the importance of temporal changes on the short-term scale determined by the factors "tide", "photoperiod" and "tidal stage" in both the survey design and choosing a sampling method.

The tidal-induced fish flux changes together with the considerable proportion of fish tracks directed against the tide indicate clearly that the tidal migration of fish was an active movement to and from intertidal areas promoted by the tide.

Our data suggest that resident mangrove fish enter the intertidal mangrove creeks at early flood tide and leave them at late ebb tide at fairly shallow water depths. The estuarine fish enter and leave the upper reaches of the mangrove channel when water level was about $2 \mathrm{~m}$ above the previous LW level, thus requiring a minimum water depth for tidal migration. At HW, maximum habitat accessibility, reduced current speeds and maximum visibility probably helped in the foraging of pelagic and benthic fish in the channel and hence resulted in high fish fluxes due to increased milling in front of the transducer. The time delay between immigration of resident and estuarine fish is shorter at spring than at neap tide Fig. 6. Hence, the period available for foraging and the habitat accessibility are enhanced at spring tide; both catches of fish (Davis, 1988; Laroche et al., 1997; Krumme, own obs.) and the fishes' feeding success are greater at spring tide (Colombini et al., 1996; Brenner, pers. comm.).

\section{Acknowledgements}

We would like to thank all our Brazilian and German colleagues for their cooperation. We are very grateful to Jenny Leal-Flórez, Matthias Brenner and Christoph Schaub who provided insight into their thesis' results. Special thanks go to Chico Amançio, Falko Berger, Jim Dawson (BioSonics), Andreas Hanning, Ilson, Gesche Krause, Anne Lebourges (IRD), Darlan Smith and Ulf Stühmer for help, practical support and discussions. This work resulted from the cooperation between the Center for Tropical Marine Ecology (ZMT), Bremen, Germany and the Universidade Federal do Pará (UFPa), Belém, Brazil, under the Governmental Agreement on Cooperation in the Field of Scientific Research and Technological Development between Germany and Brazil financed by the German Ministry for Education, Science, Research and Technology (BMBF) [Project number: 03F0253A5, Mangrove Dynamics-Management and MADAM], and the Conselho Nacional de Pesquisa e Tecnologia (CNPq) [MADAM contribution 47].

\section{References}

Barletta, M., 1999. Seasonal changes of density, biomass and species composition of fishes in different habitats of the Caeté estuary (North Brazilian coast-east Amazon). Bremen Univ., (FRG) Fachbereich 2 (Biologie/Chemie) ZMT Contrib. No. 7, Zentrum fuer Marine Tropenoekologie, Bremen (FRG).

Barletta, M., Barletta-Bergan, A., Saint-Paul, U., 1998. Description of the fisheries structure in the mangrove-dominated region of Bragança (state of Pará, North Brazil). Ecotropica 4, 41-53. 
Barletta-Bergan, A., 1999. Structure and seasonal dynamics of larval and juvenile fish in the mangrove-fringed estuary of the Rio Caeté in North Brazil. Bremen Univ., (FRG) Fachbereich 2 (Biologie/Chemie), ZMT Contrib. No. 8, Zentrum fuer Marine Tropenoekologie, Bremen (FRG).

Barletta-Bergan, A., Barletta, M., Saint-Paul, U., 2002. Structure and seasonal dynamics of larval fish in the Caeté River estuary in North Brazil. Estuar. Coast. Shelf Sci. 54, 193-206.

Bell, J.D., Pollard, D.A., Burchmore, J.J., Pease, B.C., Middleton, M.J., 1984. Structure of a fish community in a temperate tidal mangrove creek in Botany Bay, New South Wales. Aust. J. Mar. Freshw. Res. 35, 33-46.

Berger, U., Glaser, M., Koch, B., Krause, G., Lara, R., Saint-Paul, U., Schories, D., Wolff, M., 1999. An integrated approach to mangrove dynamics and management. J. Coast. Cons. 5, 125-134.

Blaber, S.J.M., Brewer, D.T., Harris, A.N., 1994. Distribution, biomass and community structure of demersal fishes of the Gulf of Carpentaria, Australia. Aust. J. Mar. Freshw. Res. 45, 375-396.

Cattrijsse, A., Makwaia, E.S., Dankwa, H.R., Hamerlynck, O., Hemminga, M.A., 1994. Nekton communities of an intertidal creek of a European estuarine brackish marsh. Mar. Ecol. Prog. Ser. 109, 195-208.

Colombini, I., Berti, R., Nocita, A., Chelazzi, L., 1996. Foraging strategy of the mudskipper Periophthalmus sobrinus Eggert in a Kenyan mangrove. J. Exp. Mar. Biol. Ecol. 197, 219-235.

Davis, T.L.O., 1988. Temporal patterns in the fish fauna entering a tidal swamp system in tropical Australia. Env. Biol. Fish. 21, 161-172.

Dittmar, T., Lara, R.J., 2001. Do mangroves rather than rivers provide nutrients to coastal environments south of the Amazon River? Evidence from long-term flux measurements. Mar. Ecol. Prog. Ser. 213, 67-77.

Dittmar, T., Lara, R.J., 2001. Driving forces behind nutrient and organic matter dynamics in a mangrove tidal creek in North Brazil. Estuar. Coast. Shelf Sci. 52, 249-259.

Fleischman, S.J., Burwen, D.L., 2000. Correcting for positional-related bias in estimates of the acoustic backscattering cross-section. Aquat. Living Resour. 13, 283-290.

Gibson, R.N., 1973. The intertidal movements and distribution of young fish on a sandy beach with special reference to the plaice (Pleuronectes platessa L.). J. Exp. Mar. Biol. Ecol. 12, 79-102.

Gibson, R.N., Pihl, L., Burrows, M.T., Modin, J., Wennhage, H., Nickell, L.A., 1998. Diel movements of juvenile plaice Pleuronectes platessa in relation to predators, competitors, food availability and abiotic factors on a microtidal nursery ground. Mar. Ecol. Prog. Ser. 165, 145-159.

Guillard, J., 1998. Daily migration cycles of fish populations in a tropical estuary (Sine-Saloum, Senegal) using a horizontal-directed split-beam transducer and multibeam sonar. Fish. Res. 35, 23-31.
Helfman, G.S., 1993. Fish behaviour by day, night and twilight. Second ed. In: Pitcher, T.J. (Ed.), Behavior of Teleost Fishes. Chapman \& Hall, London, Fish \& Fisheries Ser. 7, pp. 479-512.

Horn, M.H., Martin, K.L.M., Chotkowski, M.A., 1999. Intertidal Fishes: Life in Two Worlds. Academic Press, San Diego, CA.

INMET (Instituto Nacional de Metereologia), 1992. Normais climatológicas (1961-1991). Tech. Rep. Instituto Nacional de Metereologia, Brasilia DF, Brasil.

Kieser, R., Mulligan, T., Ehrenberg, J., 2000. Observation and explanation of systematic split-beam angle measurement errors. Aquat. Living Resour. $13,275-281$.

Kneib, R.T., Wagner, S.L., 1994. Nekton use of vegetated marsh habitats at different tidal stages of tidal inundation. Mar. Ecol. Prog. Ser. 106, 227-238.

Krause, G., Schories, D., Glaser, M., Diele, K., 2001. Spatial patterns of mangrove ecosystems: the bragantinian mangroves of northern Brazil (Bragança, Pará). Ecotropica 7, 93-107.

Laegdsgaard, P., Johnson, C.R., 1995. Mangrove habitats as nurseries: unique assemblages of juvenile fish in subtropical mangroves in eastern Australia. Mar. Ecol. Prog. Ser. 126, 67-81.

Laroche, J., Baran, E., Rasoanandrasana, N.B., 1997. Temporal patterns in a fish assemblage of a semiarid mangrove zone in Madagascar. J. Fish Biol. 51, 3-20.

Levy, D.A., Cadenhead, A.D., 1995. Selective tidal stream transport of adult sockeye salmon (Oncorhynchus nerka) in the Fraser River estuary. Can. J. Fish. Aquat. Sci. 52, 1-12.

Louis, M., Bouchon, C., Bouchon-Navaro, Y., 1995. Spatial and temporal variations of mangrove fish assemblages in Martinique (French West Indies). In: Wong, Y.S., Tam, F.Y. (Eds.), Asia-Pacific Symposium on Mangrove Management, pp. 275-284.

Morrison, M.A., Francis, M.P., Hartill, B.W., Parkison, D.M., 2002. Diurnal and tidal variation in the abundance of the fish fauna of a temperate tidal mudflat. Estuar. Coast. Shelf Sci. 54, 793-807.

Robertson, A.I., Duke, N.C., 1987. Mangroves as nursery sites: comparisons of the abundance and species composition of fish and crustaceans in mangroves and other nearshore habitats in tropical Australia. Mar. Biol. 96, 193-205.

Rountree, R.A., Able, K.W., 1992. Foraging habits, growth, and temporal patterns of salt-marsh creek habitat use by young-of-year summer flounder in New Jersey. Trans. Am. Fish. Soc. 121, 765-776.

Sasekumar, A., Chong, V.C., Leh, M.U., D'Cruz, R., 1992. Mangroves as a habitat for fish and prawns. Hydrobiologia 247, 195-207.

Spalding, M., Blasco, F., Field, C.D. (Eds.), 1997. World Mangrove Atlas. International Society for Mangrove Ecosystems, Okinawa. 